\section{Understanding the Neighbourhood Choice DECISIONS OF MOVERS: AN ANALYsis of Focus GROUP DISCUSSIONS}

Zahid Sultan*, Mehdi Moeinaddini, Zohreh Asadi-Shekari, Muhammad Zaly Shah

Department of Urban and Regional Planning, Faculty of Built Environment, Universiti Teknologi Malaysia, 81310 UTM Johor Bahru, Johor, Malaysia
Article history

Received

6 July 2015

Received in revised form

5 August 2015

Accepted

1 September 2015

*Corresponding author

zahids@utm.my

\begin{abstract}
Using a qualitative methods approach, this study explores the key factors that influence household neighbourhood choice. Three newly developed residential neighbourhoods have been studied to examine resident decision making around their neighbourhood preferences. Four focus group $(n=4)$ discussions with 29 individuals who were recent movers to the study areas were conducted to examine the reasons behind neighbourhood choice and the needs of the household. The results revealed that household neighbourhood choice decisions were multi-faceted and complex. The key findings can be classified into six categories: safety, residential environment, neighbourhood facilities, accessibility, economic and demographic factors. Residents emphasised that the combination of land-use and transportation planning may be one important part of multi-layered solutions to improve quality of life in residential neighbourhoods.
\end{abstract}

Keywords: Neighbourhood choice, safety, residential environment, focus group

(C) 2015 Penerbit UTM Press. All rights reserved

\subsection{INTRODUCTION}

Mobility is a fundamental need of human beings. Spatial distribution of activities, services and shopping centres influences people's choice of travel modes. In recent years, the rapid progress of urbanisation and suburbanisation has brought about a large number of urban problems such as congestion, urban sprawl and a relatively low availability of neighbourhood facilities in the new developed communities which can reduce the quality of life associated with a particular urban environment and also subsequently have a negative impact on personal mobility [1, 2]. The key reason for changing the residential location is often conceptualized as a mismatch between household residential needs/ preferences and the characteristics of its current housing situation [3]. Most of the housing studies literature has identified that a change in household demographics leads to a need for residence change [4].
However, the motives behind the change in residential location greatly differ from family to family. Some recent studies underline the role of neighbourhood characteristics as a decisive factor in understanding residential mobility [5-8]. There is also a strong relationship between stage of family life cycle and propensity to move. Statistics from developed countries show that young adults are the most frequent residential movers. Some empirical studies suggest that dwelling characteristics and families' socio-economic characteristics are possibly more influential than accessibility $[9,10]$. A few studies have also identified that change in household composition (e.g., getting married, birth of children, divorce) can force individuals to change the place of residence [11]. Although a qualitative investigation to identify any connection between residential location choice (RLC) and travel behaviour of households is not entirely new however, very few qualitative studies are to be found in urban planning literature. 
Recently a study in the UK using focus groups (FG) was conducted to explore the residents' experiences of 'home zone' in a deprived neighbourhood with a particular focus on aspects of quality of life and physical activity participation. Results from this work show that 'home zone' design has a very low influence on physical activity. Car based mobility was dominant factor and residents valued highly factors such as socio-environmental, neighbourhood safety and poor public transport provision [12]. The value of natural and open landscape characteristics were explored by using FG in a study on decision mechanisms of homeowners in Michigan, USA [13]. To better understand the underlying decisions upon which these prevailing patterns of development are based, new home buyers were asked about the importance of home, neighbourhood, and community features in their recent decision to purchase a home at urban fringe. The study found that home buyers with high household incomes and those living in rural townships tended to rate natural and open spaces higher as a preference factor in home buying decisions than other income and geographic groups. This study underlined the preference of natural and open space for rural dwellers compared to the accessibility to neighbourhood facilities (school, health centre) and housing features [13]. In the Netherlands, a research study by using four FGs with 38 participants was conducted to explore the perceptions of environmental influences on health behaviour patterns across socioeconomic groups [14]. Results show that people from lower socioeconomic backgrounds reported poor neighbourhood aesthetics, safety concerns and poor access to facilities as barriers for being physically active. A study collected data by interviewing seventeen different stakeholders (land developer, city spatial planners, etc.) related to neighbourhood development [15]. Results showed that participants supported mixed neighbourhood design with higher density, greater connectivity, and increased access to neighbourhood facilities. The research has also identified salient barriers to the development of prophysical activity neighbourhoods included a lack of financial resources, lack of public and stakeholder awareness, and existing social norms.

A myriad of factors have been identified which influence key determinants in the household decisions around neighbourhood choice. The international research literature has, however, persistently emphasised the importance of key factors which motivate households to locate in a particular area namely: neighbourhood facilities, residential environment, accessibility, socio-economic factors and social status such as lifestyle [16-19]. This paper, therefore, contributes to expanding the knowledge of a wide range of issues associated with households' neighbourhood choice and their travel pattern

\subsection{MATERIAL AND METHOD}

Four FG discussions were conducted in order to understand movers' neighbourhood choice decision in three newly developed residential neighbourhoods with distinct typology in Northern Ireland. FGs have been described as a 'carefully planned discussion designed to obtain perceptions on a defined area of interest in a permissive, non-threatening environment [20]. Data generated through the FG discussion is unique in the sense that it represents information both from the individual, and from the individual as part of a larger group. Some researchers suggest that every single person's opinion and perception express a larger social context [21,22] and the group serves as the fundamental unit of analysis [23]. However, some researchers criticise the lack of detailed information in data analysis and interpretation [24-26].

Following Krueger [20], 6-10 movers were drawn for this study from each case study area. The selected participants who represented a particular household were invited at a suitable place in their respective areas to discuss their motives/attitudes about residential mobility. This study has sought to reveal the range of significant factors which are important for land-use planning/transportation policy in the region. These include: perceived importance of residential environment (safety, quietness, greenery); value of neighbourhood facilities (proximity to: public transport, education, health and shopping centre); concerns about children's physical fitness (park, recreational areas) and socio-demographic as well as attitudinal factors. These key factors are considered primary motivates behind the RLC decision of the movers but this paper is not confined to these factors. Each FG discussion focused around a topic guide and the resultant data were classified according to key themes and emergent categories. High priority factors were refined by comparing similarities and differences within groups, and across data sources. For a better interpretation of $F G$ results and to make analysis more transparent, and for better analysis of latent variables, FG raw material transcripts should be divided into three levels namely: articulated, attributional, and emergent data [27]. Direct response to the questions is defined as articulated data, which is the descriptions, interpretations, and comments of participants in their own words. Whereas results of priori theories, hypotheses or research questions that the researcher wants to analyse, are referred to as attributional data. The term emergent data is defined as that data which contributes to new insights and hypothesis formulation and is the unanticipated product of individual comments and exchanges among group members. Participants' unspoken cultural perspectives and normative values (beliefs, attitudes, and behaviours) can be included in this type of data. During data interpretation, participants' quotes and comments may suffice for articulated data but detailed description of the comments with explanation is necessary for attributional data [27]. 


\subsection{Study Area Characteristics and Geographic Sampling}

Three newly developed neighbourhoods in Northern Ireland with quite distinct residential and accessibility characteristics were selected for this research. Ravenhill Road neighbourhood is a densely populated area with 470 housing units, situated within Belfast city with easy access to the main metro bus line. Some recreational areas and nearby shopping centre are easily accessible with public transport. The Ambleside neighbourhood is a rural area situated at the fringe of Carrickfergus. It has very low public transport (PT) accessibility, limited neighbourhood facilities but the area is full of natural sceneries. It is a modern residential location consisting of 326 detached houses with plenty of outdoor space. Ballynure Road site is a newly developed residential site with 242 housing units in the district of Newtownabbey. It is suburban area in the district of Newtownabbey near Belfast, with easy access to local shopping centre. Main selection criteria for the case study areas were the accessibility level of public transport, proximity to neighbourhood facilities and residential environment as shown in Table 1.

Table 1 Selected neighbourhoods

\begin{tabular}{ccccc}
\hline Locations & $\begin{array}{c}\text { Neighbourhood } \\
\text { area }\end{array}$ & District & $\begin{array}{c}\text { No. of Housing } \\
\text { units }\end{array}$ & $\begin{array}{c}\text { Site area } \\
\text { (hectares) }\end{array}$ \\
\hline Urban & Ravenhill road & Belfast & 470 & 5.56 \\
Suburban & Ballynure road & Newtownabbey & 242 & 10.4 \\
Rural & Ambleside & Carrickfergus & 326 & 20.3 \\
\hline
\end{tabular}

\subsection{Participants Selection Criteria}

It was important to represent main sociodemographic groups (age, gender, family set up, employment) from the sample population in each neighbourhood. Young adults and married couples aged 21 and above who changed the residence during the last 5 years and chose to reside in urban or rural area of Northern Ireland (NI) were selected. The participants were categorized into four groups:

- Couple

- Couples with children
- $\quad$ Single Parent

- Single

In order to have desired representation in each FG, the researcher approached the families/individuals in the case study area to request their attendance at the FG discussions. Individuals were approached with shared key characteristics pertinent to the study and each FG comprised between six to nine participants who were unknown to each other. Table 2 shows the composition of participants in each FG.

Table 2 Focus group participants

\begin{tabular}{lcccc}
\hline \multicolumn{1}{c}{ FG Participants } & $\begin{array}{c}\text { FG-1 } \\
\text { Ambleside }\end{array}$ & FG-2 Ballynure & $\begin{array}{c}\text { FG-3 Ravenhill } \\
\text { Road }\end{array}$ & $\begin{array}{c}\text { FG-4 Ravenhill } \\
\text { Road }\end{array}$ \\
\hline Total participants & 7 & 6 & 9 & 7 \\
Male & 3 & 4 & 6 & 4 \\
Female & 4 & 2 & 3 & 3 \\
$21-30$ & 0 & 0 & 2 & 2 \\
$31-40$ & 1 & 1 & 3 & 1 \\
$41-50$ & 2 & 2 & 3 & 3 \\
$51-65^{*}$ & 4 & 3 & 1 & 1 \\
House owner & 7 & 4 & 5 & 3 \\
Rental & 0 & 2 & 4 & 0 \\
Single & 1 & 0 & 1 & 2 \\
Couple & 1 & 2 & 3 & 2 \\
Couple with Kids & 3 & 4 & 3 & 3 \\
Single parents & 2 & 0 & 2 & \\
\hline
\end{tabular}

(*Young adults and married couples aged 21 and above were invited; no participant was above 65 years)

\subsection{RESULTS}

\subsection{Articulated Analysis}

Data analyses were performed following the framework approach of Massey [27]. Special emphasis was given to statements that were discussed in detail, intensity and with great specificity by different participants within one focus group, and/or by participants over different focus groups [20]. FG discussions centred on residents' reasons for current neighbourhood choices. Participants in all FGs were asked to identify the main features they liked in their current neighbourhood. The rationale behind this was 
so that a better understanding of the prominent aspects of their neighbourhood and to investigate a broader ranges of issues that underpin household lifestyle. Also this allowed some understanding of the value attached to accessibility and connectivity of transport infrastructure and/or land use systems within their neighbourhood. This analysis identified 4 prominent factors by which influence the perception of neighbourhood choice decisions: (i) residential environment, (ii) accessibility, (iii) neighbourhood facilities and (iv) cost. Overall, it was noted that the majority of participants were contented regarding their decision of neighbourhood choice.

\section{(a) Residential Environment}

In residential environments, features such as safety, garden/countryside and quietness provide comfortable and pleasant living environments for residents. Comfortable physical residential environment is one of the main factors studied by researchers to explain the residential location preferences $[28,29]$. For the participants in this study, particularly families with children, safety was a primary concern. However, neighbourhood facilities, family budget and housing characteristics were also considered key elements in RLC. Neighbourhood safety was a key issue raised by many participants persistently from Ballynure and Ravenhill Roads neighbourhoods.

\begin{abstract}
'We have two young boys and they need area to play nearby. Kids' safety is also very important. I love to live in a rural area and I do not mind travelling. I am not interested in living in or near to the city centre. Living outside has better living standards' (Female 33 years, Ambeside)

'I moved from a rural area to here (Ballynure) because of my job in Abbeycentre but teenagers make problems time to time in nearby areas (Glengormley), though personally in this area I do feel secure in this area but some news disturb (violence).....' (Female 43 years, Ballynure)
\end{abstract}

Northern Ireland, particularly the Greater Belfast region has a long history of ethno-political conflict. Although the situation has improved significantly during the last decade but sporadic violence nonetheless continues in some places. This situation has an impact on ordinary people. Therefore, parents are particularly concerned in this regard. In this context, the FG participants indicated a general preference of housing location in the areas which are considered less troublesome.

\section{(b) Accessibility}

The participants from Ballynure and Ravenhill Roads indicated that easy access to efficient public transport provides more options for visiting the city centre particularly within peak hours. An easy access to the goods and service centres in their living areas also acted as an influencing factor for their RLC decision.

\begin{abstract}
'Now that the children are grown-up, the size of house is not important, but it must still be near public transport and in a mixed area' (Male, 62 years, Ballynure).

'When I think for my situation the railway station is very important because it is only 10 minutes away and I walk to it every morning to get a train to University of Ulster Johor Town (UUJ) at 7.45 am' (Female 34 years, Ravenhill)
\end{abstract}

Participants from Ambleside area demonstrated high car dependent attitude probably the area has low accessibility to public transport whereas travel patterns of Ballynure and Ravenhill Roads participants revealed significant influence of existing good quality public transport system in their daily travel activities.

\section{(c) Neighbourhood Facilities}

Participants with families reported the importance of local shop and primary school within the walking distance from residence. According to some participants a good quality school nearby could enhance the property value. The participants identified number financial benefits of neighbourhood facilities. One male participant mentioned that housing demand is always high in a peaceful neighbourhood with walking distance to primary school. The participants from Ravenhill Road areas explicitly expressed that a good quality school was important factor in housing choice decision.

'If school and shops are nearby, it is easy to find good tenant. Property is a future investment; neighbourhood facilities increase the financial value' (Male 56 years, Ballynure)

\begin{abstract}
'We wanted to be able to walk to a good local primary school and to be on public transport routes so the children could independently travel to primary / secondary / tertiary education' (Female, 37 years, Ravenhill)

'Access to local shops is relatively important to me although being a car driver not an absolute necessity. For some of my elderly neighbours though the local shops are extremely important due to reduction in public transport' (Male 27 years, Ballynure)
\end{abstract}

From these statements, it can be concluded that the young and old residents alike highly value the neighbourhood facilities. There appear to be two reasons for this: (i) parents want their children visit education centres independently; (ii) availability of neighbourhood facilities like schools, health, local shops and park in a residential scheme or nearby add to the value of the property. 


\section{(d) Socio-economic Factors}

People change their residence as family requirement demands. Generally age, marital status and employment circumstances generate the need for residential relocation. To establish any connection between RLC and socio-economic factors, researcher observed several examples across all four FGs. There was strong relationship between the stage of family life cycle and the propensity to move. Household residential satisfaction was also dependent on overall monthly income and house ownership. Mostly participants were financially active; a few participants explained that their partners were also in job which was an extra motivator to move into a new house.

'if you do not have job (money), you cannot think about own house...you have to pay the monthly mortgage and other family costs'(Male, 42 years, Ambleside)

Moreover, some participants indicated that change in their personal life such as marriage was the reason to move somewhere and then the proximity to neighbourhood facilities led them to move to their present location.

\subsection{Aftributional Analysis}

Some theories and hypotheses were also tested during the FG discussions and the results are labelled attributional data. Attributional data is proposition or hypothesis driven, therefore, extra care is required to construct the questions which provide opportunities for participants to touch on the areas of interest [27].

(i) Expectancy-value theory suggests that people adjust themselves into the neighbourhood according to their expectations (beliefs) and evaluations. This theory predicts that, when more than one option (behaviour) is possible, the option chosen will be the one with the largest combination of expected success and value for people [30,31]. Question was framed from the context of expectancy-value theory as 'what were/are the main attractions for you in your neighbourhood?'

\footnotetext{
'This neighbourhood is far better than previous one. Here it's quiet, peaceful atmosphere, children are safe. There are many other advantages to live here, you know, we also have plenty of space and sea nearby. These were the things I always dreamt about in my life. The only problem we have is grocery store and doctors. We go for shopping on Saturday and pick the stuff for whole week........car usage has increased but we are satisfied here' (Female, 42 years, Ambleside)
}

'There are many attractions in this area: Abbeycentre, Belfast city, Motorway and Airport all are nearby. It takes me 15 minutes to reach these facilities. I am frequent flyer, therefore, easy access to Belfast international airport was important for me.
Moreover people are nice... we have lot of facilities within walking distance. These also increase the resale value of the property' (Male, 47years, Ballynure)

The above mentioned statements highlighted the expectations (beliefs) and evaluations of residents. It showed that people chose to live in the neighbourhood which they felt had the highest expectancy-value for them.

(ii) Planned behaviour theory says that individuals make their decision about a particular transport mode choice and neighbourhood on the basis of systematic analysis of available alternatives [32]. This theoretical context was used to understand the change in travel behaviour (if any) after residential mobility. Participants were asked to identify any change in their travel patterns due to neighbourhood change.

\footnotetext{
'The bus station is five minutes from where I live, for city centre; I normally use public transport because it is not easy to find free parking during day time. Compared to previous place, now I use less car' (Male, 29years, Ravenhill)

'I bought first time weekly bus ticket after moving in this area. I used to buy bus ticket during weekend to attend the parties in Belfast but was never frequent public transport user' (Female, 31 years, Ballynure)
}

Behavioural intention comprises of three main factors namely: attitude to the behaviour (individual's positive or negative evaluation of performing a behaviour), subjective norm (perceived social pressure to perform the behaviour) and perceived behavioural control (perception of whether it is feasible to perform the behaviour). In relation to neighbourhood choice, it was reported that individuals were more likely to adopt a particular location if they had attractive evaluation, perceived social pressure and believed it was a viable option. People had a stronger intention to show behaviour that they evaluated favourably (positive attitude) than behaviour that they evaluate unfavourably (negative attitude).

\subsection{DISCUSSION}

The strength of the FG method is its capacity to uncover the unique trends and attitudes that determine the complexity of social situations. Overall the factors which were discussed in great length, with great intensity, on different points in time during the FG, by different participants are pointed out in the Table 3. The residents see their neighbourhoods as a place to live from the perspective of safety, calmness, greenery and proximity to job. Accessibility to PT infrastructure is found to be less important particularly for the participants living in the rural area. 
'Without car it is hard to survive in rural areas...... monthly we spend a lot on fuel but have no option. There are only limited buses during week days, situation is even worse on Sundays and we also do not have trains in this area'. (Female, 56 years, Ambleside)

'The real drawback of living in this (rural) area is lengthy trip thus more cost ...there is no viable transport really...' (Male, 41 years, Ambleside)

Introduction of the daily, weekly and monthly tickets on Metro bus service as well as on $\mathrm{NI}$ Railway was found to be a good policy instrument which being used to dissuade car usage and increase PT for multiple trips. However, this policy benefit was mainly restricted to the Greater Belfast Area (GBA) and people living out of GBA were captive to private transport. A few individuals expressed the substantial change in physical activity, or increases in active travel whereas car based travel behaviour remained dominant. However, location of services and activities from their residence was found to be helpful in reduction of trip length. Proximity to neighbourhood facilities has positive impact on household travel time and cost, although most participants reported travel time as key factor relative to travel cost. Residents emphasised on the provision of food stores, services and safe public transport access at walking distance.

General perception of FG participants can be summed up as: the suburban and rural participants were more concerned with the acquisition of space whereas participants living in the city emphasised more on time factor, for example, location of various facilities (e.g. school, health centre and job). Of course, there are many other considerations involved. In this context, in response to two different questions namely, (i) 'reasons for the move from the former residence' and (ii) 'reasons for the move to the present resident': participants from rural area mentioned the key reasons as space and natural view: and families with children valued the space (playing area for children) highly. Table 3, shows the summery of key factors and their importance level related to neighbourhood choice, as pointed out by FG participants. Five key factors and a number of subfactors stand out. Neighbourhood safety, space and travel time were reported persistently as the key factors for neighbourhood as well as residential choice for families particularly with children as shown in Table 3.

Table 3 FG Participants' key neighbourhood choice factors and their importance level

\begin{tabular}{|c|c|c|c|c|}
\hline \multirow[b]{2}{*}{ Neighbourhood Choice Factors } & \multicolumn{4}{|c|}{ Demographic Categories } \\
\hline & Singles & Couple & $\begin{array}{l}\text { Couples with } \\
\text { Children }\end{array}$ & $\begin{array}{l}\text { Single } \\
\text { Parents }\end{array}$ \\
\hline \multicolumn{5}{|l|}{ Residential Environment } \\
\hline Quietness & + & + & + & + \\
\hline Greenery & + & ++ & ++ & + \\
\hline Neighbourhood safety & + & + & $+++^{*}$ & $+++*$ \\
\hline Scenic attractiveness of the area & 0 & ++ & ++ & + \\
\hline Space (indoor and outdoor) & 0 & + & $+++^{*}$ & $+++^{*}$ \\
\hline \multicolumn{5}{|l|}{ Accessibility } \\
\hline Proximity to transport facilities & ++ & 0 & ++ & 0 \\
\hline Access to city centre & ++ & + & - & - \\
\hline Proximity to social life & ++ & ++ & + & + \\
\hline \multicolumn{5}{|l|}{ Neighbourhood facilities } \\
\hline Distance to shopping area & + & 0 & + & 0 \\
\hline Health centre & ++ & ++ & ++ & ++ \\
\hline Recreational facilities & 0 & + & ++ & ++ \\
\hline Train station/Bus stop & + & 0 & + & ++ \\
\hline Education centre, (e.g. Uni., schools) & ++ & 0 & +++ & ++ \\
\hline \multicolumn{5}{|l|}{ Socio-economic Factors } \\
\hline Affordability & - & 0 & -- & -- \\
\hline Prospects for increased real estate Prices & ++ & ++ & ++ & 0 \\
\hline (mortgage, rent) & +++ & ++ & ++ & ++ \\
\hline Size of the property & ++ & ++ & ++ & ++ \\
\hline Style of the house & 0 & ++ & + & 0 \\
\hline People with similar background & + & - & ++ & + \\
\hline Closeness to family \& friends & + & ++ & + & ++ \\
\hline \multicolumn{5}{|l|}{ Travel time and Cost } \\
\hline Close to job place & ++ & ++ & ++ & ++ \\
\hline Close to partner's job place & 0 & + & + & + \\
\hline Travel costs & + & + & ++ & ++ \\
\hline Travel time & ++ & +++ & $+++^{*}$ & +++ \\
\hline
\end{tabular}

Notes: key to the signage/legend used in the table is as follows:

0 factor of no importance (not mentioned)

- or + factor of minor importance (less/high)

- - or ++ factor of importance

+++ factor of high importance (* factor was repeated persistently)

The importance was judged from whether or not the factor was discussed in great length, with great intensity, on different points in time during the FG, by different participants within one focus group, and/or by participants over different focus groups. 
For young professionals, travel time to work and other facilities were important perhaps due to their busy lifestyle whereas for retired people distance rather than time to access the facilities was highly valuable. Though, the socio-economic factors played important role in neighbourhood choice but household safety emerged as a single motivating factor for majority of participants. Family oriented residents, neighbourhood safety was cited as a significant determining factor and sub-factor here included graffiti, crime, street design, and the perceived vulnerability of children.

'many locations in Belfast are not safe particularly for children' (Female, 34 years, Ravenhill)

'other nearby residentional neighborhoods are full of flags and graffiti... we noticed that teenagers have tendency to get influenced' (Female, 46years, Ballynure)

In nutshell, participants mentioned a wide range of problems associated with overall spatial planning in the region and mobility barriers. These problems are multi-dimensional which include design of the built environment (unbalanced distribution of residential lots and neighbourhood facilities), journey time, poor inter modal connectivity to access activity destinations, safety issues, financial constraints, perception about PT (reliability and delays) and weather conditions.

\subsection{CONCLUSION}

The FG discussions are a fundamental tool to better understand the perceived reality and allowed the researcher to study the participants' behaviour about neighbourhood choice with respect to household travel patterns. The study provides insights for planners to improve neighbourhood design according to the preferences of the users. The dependency on car as predominant travel mode was clearly evident in residential neighbourhood choice. This may be attributed to several factors. First, Northern Ireland's built environment structure entices residents for car use because of spatial distribution of activities and services. Second, PT is not efficient enough to fulfil the requirements to access the key activity and service centres. As a result, residents select the residential neighbourhood keeping in mind car based accessibility. The FG discussions indicated the potential for the sustainable neighbourhood design by integrating land-use planning and transportation system in breaking the cycle of increasing car dependence.

A number of factors associated with neighbourhood choice were identified by the participants that strongly motivate people to live in a particular neighbourhood. These include safety, outdoor space for children, serenity and quietness, neighbourhood facilities, residential environment and
PT accessibility. This study found that rural residents valued open space, greenery and quietness highly in their life whereas proximity to neighbourhood facilities and PT were low priorities. This is probably because of Iow PT availability in rural areas and their established habits of car dependency to fulfil their daily travel needs. Though government has introduced new transport polices (e.g. free travel pass for senior citizens, integration of transport modes, integrated ticket systems and daily/weekly/monthly tickets) but the research found that the impact of these policies is nominal at rural level in neighbourhood choice. However, the impact of these policies was considerable in suburban and urban neighbourhoods. Travel cost was valued less by the participants overall; however, travel time to reach job place, and other services as well as activity centre was reported as key factor in younger/working age participants' neighbourhood choice decision. Most participants were interested in using car as a basic mode of transport whereas neighbourhood facilities and PT accessibility were found to be important from real estate market viewpoint rather overall car trips reduction.

\footnotetext{
'The public transport or school is not important for me but was a factor in my purchase. The fact that I am a street away from a primary school might make the house easier to sell. Proximity to shopping area and hospital will affect the resale value of my house' (M. 58, Ballynure)
}

This paper has shown the importance of public participation in developing the policies related to the residential neighbourhoods as it is the people who bear the brunt of the policy outcomes. The FG participants provided quality information which was ideal for dealing with the subject such as neighbourhood design and household travel patterns. The FG participants' experiences and opinions pointed out some key factors which could be important for further search as well as beneficial for regional policy makers and need to be incorporated into the local land-use/transport planning for Northern Ireland.

\section{Acknowledgement}

We are grateful for University of Ulster for VCRS funding to the first author for this research.

\section{References}

[1] Bracy, N. L., R. A. Millstein, J. A. Carlson, T. L. Conway, J. F. Sallis, B. E. Saelens. 2014. Is the Relationship Between the Built Environment and Physical Activity Moderated by Perceptions of Crime and Safety? International Journal of Behavioural Nutrition and Physical Activity. 11-24.

[2] Bontje, M. 2004. From Suburbia to Post-Suburbia in the Netherlands: Potentials and Threats for Sustainable 
Regional Development. Journal of Housing and the Built Environment, 19(1):25-38

[3] Lu, M. 1998. Analyzing Migration Decision Making: Relationships Between Residential Satisfaction. Mobility Intentions and Moving Behavior. Environment and Planning A. 30: 1473-1495.

[4] Gobillon, L., H. Selod, and Y. Zenou. 2008. The Mechanisms of Spatial Mismatch. Urban Studies. 44(12): 2401-2427.

[5] Clark, W. A. V., R. C. Deurloo, and F. M. Dieleman. 2004. Choosing Neighborhood: Residential Mobility and Neighborhood Careers. Paper Presented at the European Network of Housing Research Conference, Cambridge. UK.

[6] Permentier, M., M. van Ham, and G. Bolt. 2007. Behavioural Responses to Neighbourhood Reputations. Journal of Housing and the Built Environment. 22(2): 199-213.

[7] Ham, M. van and W. A. V. Clark. 2009. Neighbourhood mobility in context: household moves and changing neighbourhoods in the Netherlands, Environment and Planning A, $41(6): 1442-1459$.

[8] Ham, M. van and P. Feijten. 2008. Who Wants to Leave the Neighbourhood? The Effect of Being Different from the Neighbourhood Population on Wishes to Move. Environment and Planning A. 40: 1151-1170.

[9] Blijie, B. 2005. The Impact of Accessibility on Residential Choice: Empirical Results of a Discrete Choice Model. In: Proceedings international Housing Conference of the ENHR. 1-25.

[10] Molin, E. and H. Timmermans. 2002. Accessibility Considerations in Residential Choice Decisions: Accumulated Evidence from the Benelux. TRB, Washington DC.

[11] Dieleman, F. M., W. A. V. Clark and M. C. Deurloo. 2000. The Geography of Residential Turnover in 27 large US Metropolitan Housing Markets, 1985-1995. Urban Studies. 37(2): 223-246.

[12] Coulson, J. C., K. R. Fox, D. A. Lawlor and T. Trayers. 2011. Residents' Diverse Perspectives of the Impact of Neighbourhood Renewal on Quality of Life and Physical Activity Engagement: Improvements But Unresolved Issues. Journal of Health \& Place. 17: 300-310.

[13] Christine, A. Vogt and Robert W. Marans. 2004. Natural Resources and Open Space in the Residential Decision Process: A Study of Recent Movers to Fringe Counties in Southeast Michigan. Journal of Landscape and Urban Planning. 69: 255-269.

[14] Carlijn, B. M., Frank J. Kamphuis, van Lenthe, Katrina Giskes, Johannes Brug and Ohan P. Mackenbach. 2007. Perceived Environmental Determinants of Physical Activity and Fruit and Vegetable Consumption Among High and Low Socioeconomic Groups in the Netherlands. Journal of Health and Place. 13: 493-503.

[15] Marianne, I. C., R. B. Tanya, S. John, N. Candace, C. Marie and B. Christopher. 2010. Key Stakeholder Perspectives on the Development of Walkable Neighbourhoods. Journal of Health \& Place. 16: 43-50.
[16] Erwin, R. and R. Cervero. 2010. Travel and the Built Environment: A Meta-Analysis. Journal of the American Planning Association. 76(3): 265-294

[17] Chen, Y., and S. S. Rosenthal. 2008. Local Amenities and Life-Cycle Migration: Do People Move for Jobs or Fun? Journal of Urban Economics. 64: 519-537.

[18] Borck, R., and M. Wrede. 2009. Subsidies for intracity and intercity commuting. Journal of Urban Economics, 66: 25-32

[19] Dahl, M. S. and O. Sorenson. 2010. The Migration of Technical Workers. Journal of Urban Economics. 67: 33-45.

[20] Krueger, R. and M. Casey. 2000. Focus Groups: A Practical Guide for Applied Research. 3rd ed. Thousand Oaks CA: Sage Publications.

[21] Hollander, J. A. 2004. The Social Contexts of Focus Groups. Journal of Contemporary Ethnography. 35(5): 602-637.

[22] Hyden, L. C., and P. H. Bulow. 2003. Who's Talking: Drawing Conclusions from Focus Groups-Some Methodological Considerations. International Journal of Social Research Methodology. 6(4): 305-321.

[23] Morgan, D. L. 1997. Focus Groups as Qualitative Research. 2nd edition. Qualitative Research Methods Series 16. Sage Publications.

[24] Myers, G., and P. Macnaghten, 2001. Can Focus Groups Be Analyzed as Talk? In R. S. Barbour \& J. Kitzinger (Eds.). Developing Focus Group Research: Politics, Theory and Practice. Thousand Oaks CA: Sage Publications. 173-185.

[25] Webb, C., and J. Kevern. 2001. Focus Groups as a Research Method: A Critique. Journal of Advanced Nursing. 33(6): 798-805.

[26] Hurworth, R. 2003. Book Review: Advanced Focus Group Research, E. F. Fern (Ed.). Evaluation and Program Planning. 26(1): $39-40$

[27] Massey T. Oliver. 2011. A Proposed Model for the Analysis and Interpretation of Focus Groups in Evaluation Research. Evaluation and Program Planning. 34: 21-28.

[28] Rioux, L. and C. Werner. 2011. Residential Satisfaction Among Aging People Living in Place. Journal of Environmental Psychology. 31: 158-169.

[29] Ge, J.and and K. Hokao. 2006. Research on Residential Lifestyles in Japanese Cities from the Viewpoints of Residential Preference, Residential Choice and Residential Satisfaction. Journal of Landscape and Urban Planning. 78: 165-178.

[30] Fishbein, M. 1968. An Investigation of Relationships Between Beliefs About an Object and the Attitude Towards That Object. Human Relationships. 16: 233-240.

[31] Fishbein, M and I. Ajzen. 1974. Attitudes Towards Objects as Predictors of Single and Multiple Behavioural Criteria. Psychological Review. 81 (1): 29-74.

[32] Ajzen, I. 1991. The Theory of Planned Behaviour. Organizational Behaviour and Human Decision Processes. 50(2): 179-211. 